\title{
RESEARCH ON THE OPTIMIZATION OF SINTERING METAL CARBIDE PROCESSING COSTS USING DIAMOND COATED DISKS WITH RESINS POLYAMIDE BINDERS
}

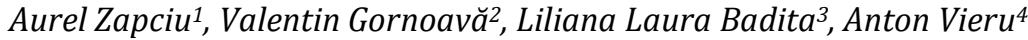 \\ 1, 2,3,4 National Institute of Research and Development in Mechatronics and Measurement Technique, \\ Bucharest, Romania, \\ E-mail: incdmtm@incdmtm.ro
}

\begin{abstract}
Sintered metal carbide (cms) products for machining as well as superabrasive materials have two essential characteristics: they are "indispensable" in the machining technique (mechanical, cold and hot plastic deformation, etc.) and they are consider as being, „usable".
\end{abstract}

Keywords: Metal Carbides, Super abrasives, Diamond.

\section{Introduction}

Under the current conditions, in order to become competitive on the competitive market, the manufacturers in the tool industry must permanently assimilate "technological innovation" and at the same time participate at their development.

SC CARMESIN SA Bucharest continues, in a very limited structure, the production of the ancien department "Sintered metal carbide plates and products" of the IMF Bucharest.

Because the highly specialized equipment, specific to the powder metallurgy technologies, existing in the current equipment are partly used morally and physically, the costs for new endowments being extremely high for the investment capability, the company makes efforts to implement the results of innovation and applied research, following optimizations sequential technological flows, able to reduce manufacturing costs.

\section{Tough Alloys}

Usually, under the generic term "hard alloys" are defined composite materials having a matrix of generally cobalt and a heavy reinforcement of $\mathrm{W}, \mathrm{Ta}$, $\mathrm{Ti}, \mathrm{Nb}$ category, present in the form of metal carbides: Wc, W2C, TiC, $\mathrm{TaC}, \mathrm{NbC}$ and complex combinations thereof. Compaction of the alloy is done by thermal sintering treatment.

This category of materials played and play a special role in the development of industrial civilization, detaching itself through a complex of remarkable features: very high hardness, tenacity, mechanical resistance and shocks, thermal stability at high temperatures, chemical stability, electrical resistance, and so on

Table 1 presents the main characteristics of carbides and nitrides of some elements in the hard alloy composition.

Tabele 1

\begin{tabular}{|c|c|c|c|c|c|c|}
\hline Formula & $\begin{array}{l}\text { Structura } \\
\text { cristalina }\end{array}$ & $\begin{array}{c}\text { Densitate } \\
{\left[\mathrm{g} / \mathrm{cm}^{3}\right]}\end{array}$ & \begin{tabular}{|l|} 
Punct de \\
fuziune $\left[{ }^{\circ} \mathrm{C}\right]$
\end{tabular} & \begin{tabular}{|l|} 
Microduritate \\
Vickers la sarc. \\
$50 \mathrm{~g}$ \\
{$\left[\mathrm{kN} / \mathrm{mm}^{2}\right]$} \\
\end{tabular} & \begin{tabular}{|l|} 
Modul de \\
elasticitate la \\
$20^{\circ} \mathrm{C}$, \\
{$\left[\mathrm{kN} / \mathbf{m m}^{2}\right]$}
\end{tabular} & $\begin{array}{l}\text { Rezistenta } \\
\text { electrica la } \\
20^{\circ} \times 10^{8} \\
{[\mathrm{H}]}\end{array}$ \\
\hline TiC & Cubica & 4,92 & 3062 & 30 & 460 & 52,5 \\
\hline $\mathrm{ZrC}$ & Cubica & 6,66 & 3420 & 28 & 350 & 50,0 \\
\hline $\mathrm{HfC}$ & Cubica & 12,67 & 3950 & 28 & 359 & 45,0 \\
\hline $\mathrm{VC}$ & Cubica & 5,48 & $\left.2700^{2}\right)$ & 21 & 430 & 65,0 \\
\hline $\mathrm{NbC}$ & Cubica & 7,82 & 3600 & 20 & 345 & 51,1 \\
\hline $\mathrm{TaC}$ & Cubica & 14,40 & 3895 & 17 & 290 & 42,1 \\
\hline $\mathrm{C}_{3} \mathrm{C}_{2}$ & Ortorombica & 6,74 & 18592) & 13,5 & 380 & 75 \\
\hline $\mathrm{Mo}_{3} \mathrm{C}$ & Hexagonala & 9,17 & 2486 & 15 & 544 & 71 \\
\hline WC & Hexagonala & 17,77 & 2776 & 17 & 710 & 19,2 \\
\hline $\mathrm{SiC}$ & $\begin{array}{l}\text { Cubica sau } \\
\text { Hexagonal }\end{array}$ & 3,22 & $2827^{2)}$ & 33,4 & 481 & $>10^{5}$ \\
\hline $\mathrm{B}_{4} \mathrm{C}$ & Romboedrica & 3,55 & 2350 & 49,5 & 434 & $10^{6}$ \\
\hline $\mathrm{Al}_{2} \mathrm{O}_{3}$ & Romboedrica & 3,97 & 2051 & 20 & 41,0 & $3,1^{12}$ \\
\hline TiN & Cubica & 5,29 & $\left.2950^{2}\right)$ & 28 & 256 & 17 \\
\hline Diamant & Cubica & 3,51 & 3727 & 78,5 & 1140 & $10^{20}$ \\
\hline
\end{tabular}

By comparing the characteristics of the hard materials presented, important conclusions are drawn:

All carbides of the analyzed metals and some nitrides have higher fusion temperatures than tungsten monocarbons, especially $\mathrm{TiC}, \mathrm{NbC}, \mathrm{ZrC}$. (3000 - $36000 \mathrm{C}$ versus $27760 \mathrm{C}$ ).

$>$ Similarly, their densities are 2.5 - 3.5 times smaller than the tungsten monocarbons

$>$ The hardness and microtubes of most carbides and nitrides are superior to tungsten carbides, the most performing diamond being carbide and boron nitride, followed by silicon carbide and nitride

$>$ The modulus of elasticity and coefficient of thermal expansion of W-monocarbons are clearly superior to the other carbides and nitrides. 
Tungsten being the most widely used fused metal, metal carbide alloys can be classified according to their presence or absence in their composition in two large groups:

$>$ tungsten hard alloys containing tungsten in the form of monocarbons or in solid solutions with other carbides

$>$ hard alloy without tungsten

In industrial practice, the processing of hard alloys from metal carbides, from mineral components to finished products, goes through the following main steps that make up the production flows presented in Figure 1.

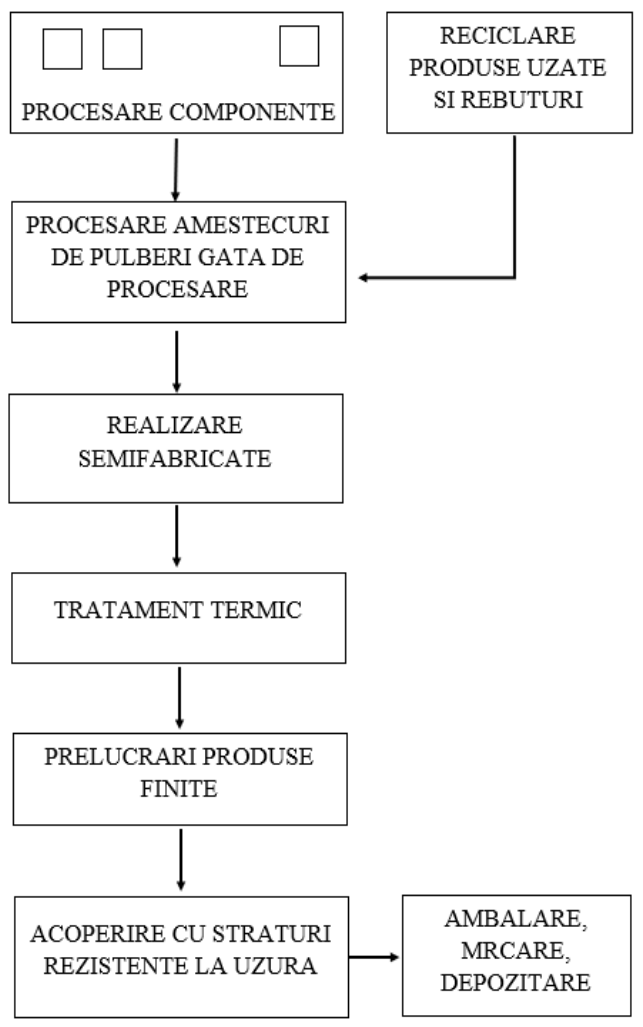

Figure 1

At present, it is estimated that the share of world consumption of sintered metallic carbide (cms) products is represented by applications in the mining industry, ca. $25-30 \%$ is destined for the manufacturing industry, consumption decreases with the expansion of the supply of products coated with wear-resistant layers and the rest are used in the other industries (chemical, steel, aerospace, special, etc.)

\section{Experimental Research}

The experimental researches were carried out in the laboratory and in the semi-industrial regime, based on an experimental program developed in advance.

The overall objective is the perfecting, through experimental determinations, of the optimized processing technology by rectification of the $\mathrm{cms}$ with superabrasive tools and a new generation binder.

For the experimental tool testing methodology, the provisions of the document "Procedure for

Operational Durability Testing of Conventional and Superabrasive Abrasives for Corrugated Abrasives", LISUM-PSL-14, elaborated by INCDMTM, are considered.

This procedure has been developed for laboratory testing, following the recommendations of ISO 17025.

For the tests in this paper that have a semiindustrial character, are stated the procedural regulations regarding:

$>$ the purpose of the testing procedure;

$>$ test method;

$>$ work equipment and measuring instruments;

$>$ consumables;

$>$ pre-trial actions;

$>$ the way of working and the recordings;

$>$ calculating, evaluating and experimenting the results.

\subsection{Creation of superabrasive grinding discs and polyamine resinoid binder}

For experimentation, a number of 3 grinding discs were made, experimental model, using 3 synthetic diamond grades, from the range D126, D151 and D181. Disks of type 1A1 150x137x20 were reused. The diamond is brittle, uncovered.

The brittle type of diamond is used for cutting hard and very harsh materials because of its ability to provide new active edges resulting from the selfsharpening tool.

The proportions of diamond, resin, green silicon carbide, resin and hardener have resulted from numerous attempts.

Green silicon carbide (Carbochim, Cluj-Napoca) has the highest purity, being manufactured with $\mathrm{SiC}>$ 98.5\%, hardness 9.5 on the Mohs scale, is somewhat tougher than black silicon carbide but more friable , which recommends it for the hard and hard metal processing (metal carbides), cast iron, ceramics, glass, rocks and concrete subjected to grinding operations. Use F60 green silicon carbide.

The resin used as a bonding agent is ROPOXID 501 - a polyamidoamine resin, purchased from Policolor SA, is unmodified liquid epoxy resin, has good stability over time and good solubility in solvents. The resin crosslinks (by using a curing agent) and strengthens at ambient temperature for a minimum of 24 hours, but crosslinking can be accelerated (1-2 hours) by heat treatment at temperatures of $60-100^{\circ} \mathrm{C}$ after a prereaction period for $2 \mathrm{~h}$.

The physicochemical characteristics of the crosslinked product are dependent on the type of hardener used. 
Optimal electrical and mechanical properties are obtained 7 days after product hardening.

Polymeric Strengthening 3361 used for crosslinking Ropoxid 501 resin is a product based on aliphatic polyalkyleneamines.

The mold in which the mixture of diamond powder, hardener resin, green silicon carbide was poured by the service provider and made at SC Carmesin SA.

Volumul de strat activ se calculeaza dupa formula The volume of active layer is calculated according to the formula

$V=\frac{\pi\left(D^{2}-d^{2}\right)}{4} \times h=\frac{3.14(22500-18769)}{4} \times 20=58576,7 \mathrm{~mm}^{3}: 1000=58,57^{3}$
$\simeq 59 \mathrm{~cm}^{3}$

where $\mathrm{D}=$ the outer diameter of the disc;

$\mathrm{d}=$ outer diameter of the disc body

$\mathrm{h}=$ active partition width

\subsection{Stages of realization of the disk}

1) The amount of diamond used is calculated using a $100 \%$ concentration, ie 4.4 carat per $\mathrm{cm} 3$ of the active layer, ie (Figure 2)

$59 \mathrm{~cm}^{3} \times 4,4 \mathrm{ct}=159,6 \mathrm{ct}, 1$ carat $=0,2 \mathrm{~g}$, deci cantitatea de diamant este $\simeq 52 \mathrm{~g}$

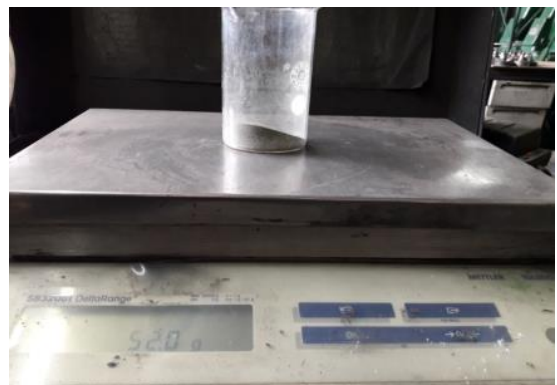

Figure 2: The weighing is carried out with the DeltaRange SB32001 electronic balance with $0.1 \mathrm{~g}$ precision from Hettler

2) Green silicon carbide is used in a proportion of $88 \%$ of the active volume

$$
59 \mathrm{~cm}^{3} \times 88 \%=52 \mathrm{~g}
$$

green silicon carbide (Fig. 3)

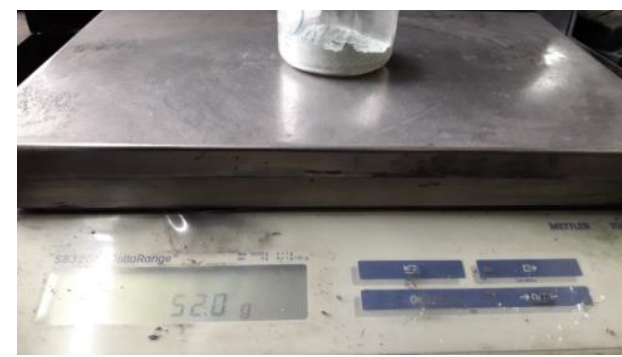

Figure 3: Weighing green silicon carbide

3) The resin participates in the mixture in proportion of $49.5 \%$ of the active volume, and the hardener in the proportion of $12.5 \%$ of the resin, that is (Figure 4):

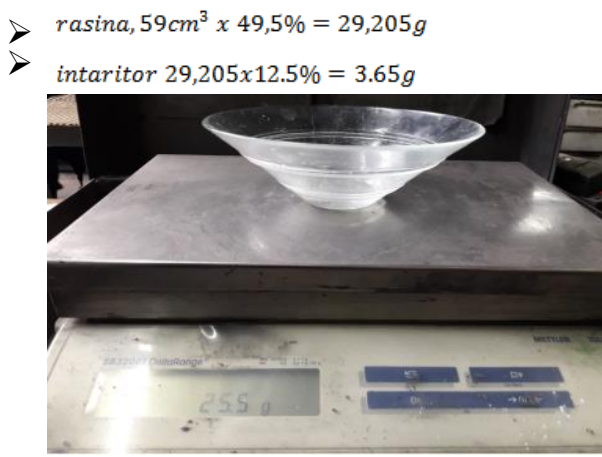

Figure 4: Weighing resin

4) The hardener is reduced by the amount of resin, so the amount of resin will be 25.5 g. (Fig.5)

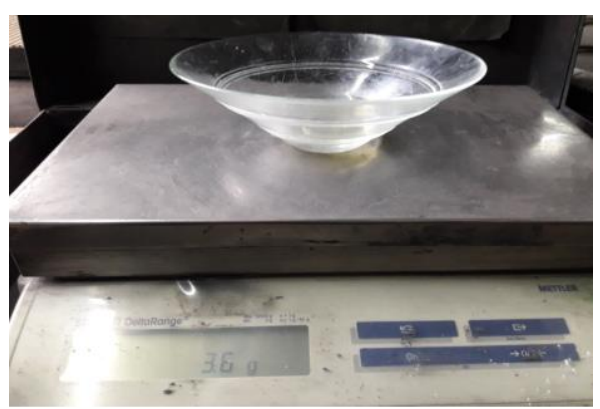

Figure 5: Weighing curing agent

5) Mixing and homogenization (Fig 6)

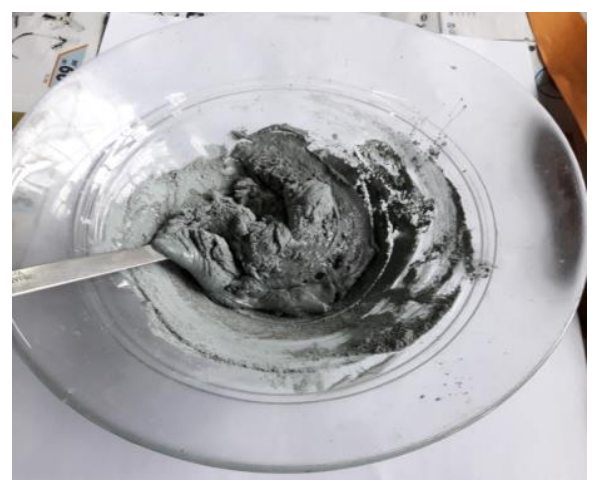

Figure 6: Preparation of mixture

6) Filling mold, forming active diamond disk layer (Fig.7)

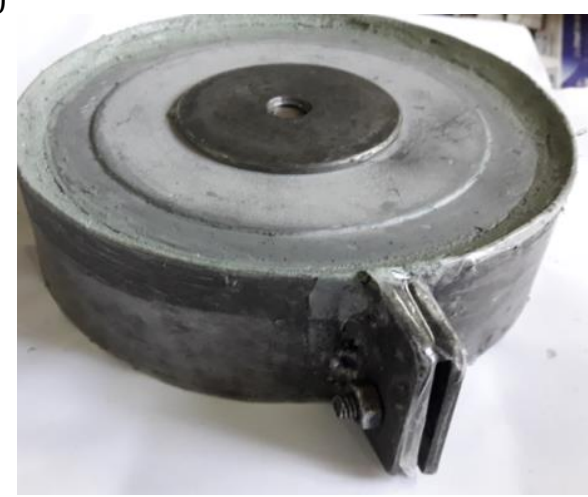

Figure 7: Matrita 
7) Preparation in the oven at $100 \mathrm{oC}$ for 1 hour for crosslinking (Figure 8)

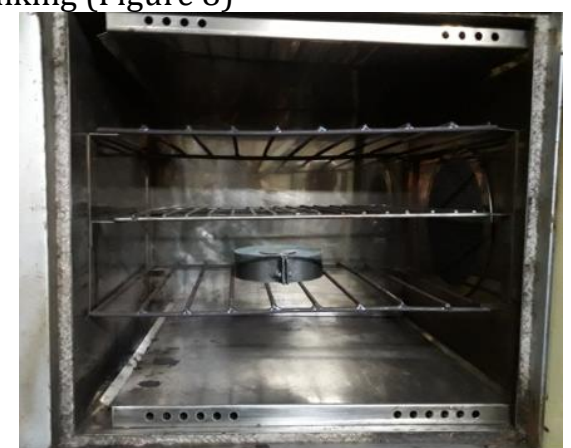

Figure 8: The oven is made from ITM-Romania

8) Abrasive disk removal from the die for processing with diamond-coated segment, active layer

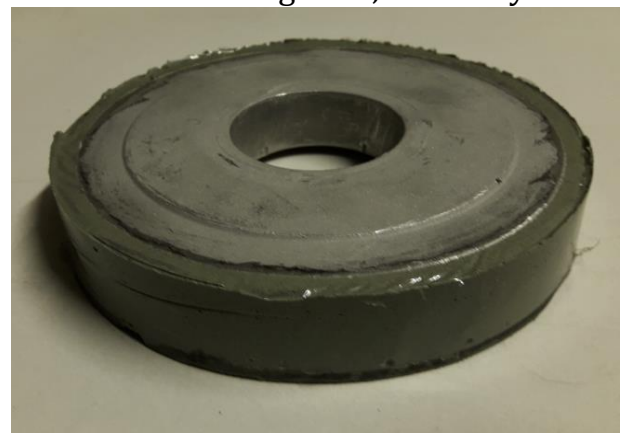

Fig. 9 Abrasive disk

9) insert the disc into the oven for 3 hours at 130140 oC (polymerization)

The results of the trials to create new-generation superabrasives and polyamide binders lead to the optimization of sintered metal carbide processing technology, both technological and economic optimization.

In order to perform the cut performance test, 6 tool positions are placed on the tool's outer diameter at 600 by drawing lines with a marker pencil and a template.

Are prepared a total of 5 specimens of $20 \times 60 \times 8$ $\mathrm{mm}$ sintered K20 metallic carbide and remove superficial defects on a grinding machine. type ELB RUBIN SCHLIFF-Germany according to the following technological flow:

$>$ sticking the resin specimens onto a magnetically fixed metal plate on the grinding machine table

$>$ mounting the 1A1 D126 R100 flat grinding wheel on the pallet flange

$>$ adjusting machine tools to the recommended work parameters:

- Peripheral speed: VS = 20 - $25 \mathrm{~m} \cdot \mathrm{s}-1$;

- longitudinal feed: UT = 12 - $15 \mathrm{~m} \cdot \mathrm{min}-1$;

- transversal feed: $b=5 \mathrm{~mm}$;

- Processing depth: $0.01 \ldots 0.05 \mathrm{~mm}$

$>$ simultaneous correction of specimens to remove superficial defects detach the specimens and stick them on the opposite face

simultaneous correction of specimens to remove superficial defects

Calculate the number of passes required to ensure that a volume of $\min . \Delta \mathrm{VW}=30,000 \mathrm{~mm}$, which ensures measurable and reproducible linear wear on the abrasive disc.

For sampling of $30,000 \mathrm{~mm} 3$ carbide material, the specimens should be processed at depth of hw = $\Delta \mathrm{VW} / \mathrm{Ar}=30,000 / 6000=5(\mathrm{~mm})$

The thickness of the material layer to be drawn is determined by measuring the position of the grinding surface of the specimens, using the front mounted micrometer on the grinding table

The active layer volume of the tool, $\mathrm{V}_{\mathrm{a}}$ $V_{a}=\pi \cdot D \cdot b_{s} \cdot X(\mathrm{~mm} 3)$ where :

$>$ D - the diameter of the $\operatorname{disc}(\mathrm{mm})$;

$>$ bs - the width of the active layer (mm);

$>\mathrm{X}$ - the thickness of the active layer $(\mathrm{mm})$;

The volume of used active material, $\Delta V s$, can be calculated or determined by measurement using a micrometric fingerprint reader measuring 6-point wear at 600 on the abrasive disc.

$$
\Delta V_{S}=\frac{\pi \cdot D \cdot b_{s} \cdot \Delta_{r s}}{1000} n m 3
$$

in which: $\Delta$ rs - average linear wear of the active layer (10 -3 mm);

Correction efficiency

$$
G=\frac{\Delta V_{W}}{\Delta V_{S}}(\mathrm{~mm} 3 \cdot \mathrm{mm}-3)
$$

The measurement results have a high confidence level of $95 \%$, due to the following reasons:

$>$ the test is carried out on a precision test machine

$>$ the measurements are made with metrologically certified equipment and checked before the test begins, and the measurement uncertainties may not be possible.

Two recipes with different percentages of resin and hardener have been experimented in order to determine the optimal one. The results were centralized in Table 2.

Table 3 presents the centralization of the experimental results.

\begin{tabular}{|c|c|c|c|c|}
\hline \multirow{2}{*}{$\begin{array}{c}\text { Binder } \\
\text { type }\end{array}$} & \multicolumn{4}{|c}{ Content (grams) } \\
\cline { 2 - 5 } & Diamond & $\begin{array}{c}\text { Green } \\
\text { silicon } \\
\text { carbide }\end{array}$ & $\begin{array}{c}\text { Resin } \\
\text { Ropoxid } \\
501\end{array}$ & $\begin{array}{c}\text { Hardener } \\
\text { I3361 }\end{array}$ \\
\hline E1 & 52 & 52 & 25,5 & 3.65 \\
\hline E2 & 52 & 52 & 29,2 & 3,18 \\
\hline
\end{tabular}

K20 MICROWAVE TESTING, in order to determine the experimental indicators. 


\begin{tabular}{|c|c|c|c|}
\hline \multicolumn{4}{|c|}{ Experimental indicators } \\
\hline $\begin{array}{l}\mathrm{G} \mathrm{mm}^{3} \\
\cdot \mathrm{mm}^{-3}\end{array}$ & $\mathrm{Z} \mathrm{mm}^{3} \cdot \mathrm{s}^{-1}$ & $\begin{array}{c}\text { Ra mm } \\
\cdot 10^{-3}\end{array}$ & Th \\
\hline \multicolumn{4}{|c|}{ Trial 1} \\
\hline 15,95 & 2,22 & 0,43 & 116,90 \\
\hline \multicolumn{4}{|c|}{ Trial 2} \\
\hline 13,85 & 2,22 & 0,44 & 101,50 \\
\hline \multicolumn{4}{|c|}{ Trial 3} \\
\hline 22,74 & 2,22 & 0,46 & 166,66 \\
\hline \multicolumn{4}{|c|}{ Trial 4} \\
\hline 24,49 & 2,22 & 0,53 & 179,48 \\
\hline \multicolumn{4}{|c|}{ Trial 5} \\
\hline 21,23 & 2,22 & 0,44 & 155,59 \\
\hline
\end{tabular}

\section{- Roughness of K20 samples}

The specimens of the K20 size $20 \times 60 \times 8(\mathrm{~mm})$, having the following chemical composition (\% by weight): $\mathrm{WC}=93.35 ; \mathrm{Cr} 3 \mathrm{C} 2=0.15 ;$ Co $=6.50$; paraffin $=2.0$ have been worked. The equipements and working mode for determining the roughness were previously shown.

The specimen processing was performed with discs with friable superabrazives from D126, D151, D181, the roughness being delimited in 3 areas of the specimens. The results are shown in Table 4

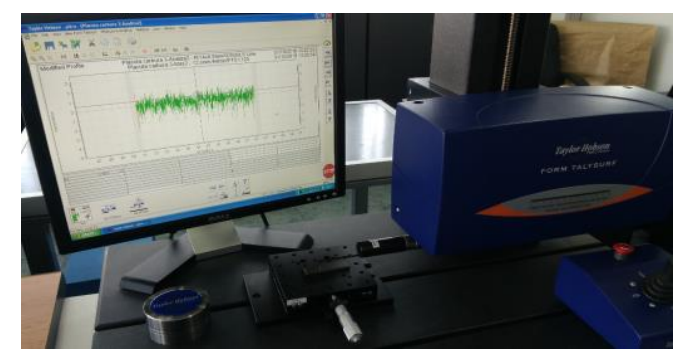

Figure 10: The ruggedness was checked with Form Talysurf 120 Taylor Hobson (INCDMTM)

Table 4

\begin{tabular}{|c|c|c|}
\hline $\begin{array}{l}\text { Nr. } \\
\text { crt. }\end{array}$ & Diamond disc & Roughness \\
\hline \multirow{3}{*}{1} & \multirow{3}{*}{ 1A1 150-20-6,5 D126 } & 0,4326 \\
\hline & & 0,4340 \\
\hline & & 0,4349 \\
\hline \multirow{3}{*}{2} & \multirow{3}{*}{ 1A1 150-20-6,5 D151 } & 0,4609 \\
\hline & & 0,4618 \\
\hline & & 0,4623 \\
\hline \multirow{3}{*}{3} & \multirow{3}{*}{ 1A1 150-20-6,5 D181 } & 0,5321 \\
\hline & & 0,5329 \\
\hline & & 0,5339 \\
\hline
\end{tabular}

\section{- $\quad$ The hardness of K20 samples}

Removal of the processing additive in case of sintered metal carbides is done by abrasion (rectification). As a result of the process heat is released that could influence the microstructure and physical-mechanical properties of the product

In order to remove this negative aspect it is necessary that the rectification process of the materials in the cms is carried out under abundant cooling. As a coolant-lubricant, a 1:50 emulsion is recommended which also has the role of removing the microscopes that are produced during the rectification, preventing the abrasive wheel from enveloping and thus improving the processing conditions

The equipement and working mode for determining the roughness were previously shown

The test specimens have the dimensions $20 \times 60 \times$ $3 \mathrm{~mm}$ remaining after the tests for determining the yield. The results obtained are presented in Table 5 .

Tests were performed to determine the hardness at 3 different points on the specimens processed with each of the diamond discs.

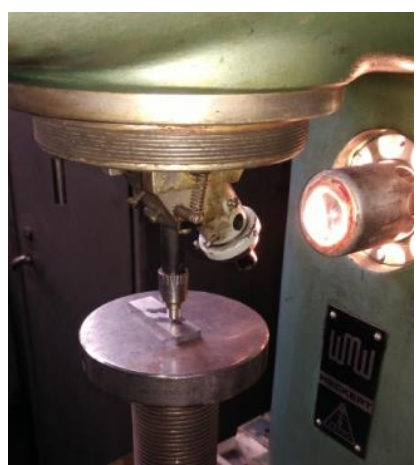

Figure 11: Determination of hardness was made with WMW Heckert, located in equipping SC Carmesin SA.

Table 5

\begin{tabular}{|c|c|c|c|}
\hline Nr. crt. & Diamond disc & $\begin{array}{c}\text { Size } \\
\text { footprint } \\
(\mathrm{mm})\end{array}$ & $\begin{array}{l}\text { Achieved } \\
\text { hardness } \\
(\mathrm{HV} 50)\end{array}$ \\
\hline \multirow{3}{*}{1} & \multirow{3}{*}{$\begin{array}{c}\text { 1A1 150-20-6,5 } \\
\text { D126 }\end{array}$} & 0,242 & 1583 \\
\hline & & 0,246 & 1532 \\
\hline & & 0,243 & 1570 \\
\hline \multirow{3}{*}{2} & \multirow{3}{*}{$\begin{array}{c}\text { 1A1 150-20-6,5 } \\
\text { D151 }\end{array}$} & 0,243 & 1570 \\
\hline & & 0,244 & 1557 \\
\hline & & 0,243 & 1570 \\
\hline \multirow{3}{*}{3} & \multirow{3}{*}{$\begin{array}{c}\text { 1A1 150-20-6,5 } \\
\text { D181 }\end{array}$} & 0,245 & 1545 \\
\hline & & 0,242 & 1583 \\
\hline & & 0,244 & 1557 \\
\hline
\end{tabular}




\section{Interpretation of Results}

Processed in real-time, real-time functional tests have generated experimental results, statistically mediated and processed based on a mathematical model, which led to the determination of process data by which the process indicators were evaluated

Five groups of experiments were performed, preliminarily considered by considering the following scientific aspects:

$>$ maintaining the structure of the technological system and the specific friction coupler

$>$ the identity of the coupler components with modification within a group of experiments with only one characteristic: the type of binder or the size of the superabrasive grain; thus making the evaluations comparable

$>$ performing experiments in similar technological conditions

$>$ performing a test tool with a reference tool: Experimental group 5, in which the tested disc was of the usual partner category, respectively a superabrasive cylindrical disc manufactured in domestic production at SC DIASFIN SA Bucharest

$>$ experimental use of the two types of binder, E1 and E2, of the new generation experimental polyamine having the structures shown in tab. 3 differentiated in terms of resin and hardener contents

$>$ the first two groups of experiments (1 and 2) led to a first value grading: the yield of processing with the tool having binder E1 resulted above that of the E2 binder. Similarly, the "Z" debit cutters, the "Ra" superficial roughness and the "T" operational durability resulted were superior. As a result, in the tests in groups of experiments 3 and 4 the tools with E1 type binder were tested;

$>$ the microsquared "sample" component was made of the same type of cms - K20 according to ISO.

$>$ the volume of material taken from the specimen was identical for all 5 groups of experiments: $30 \mathrm{~cm}^{3}$.

\section{Conclusions}

The experiments investigated the characterization of the efficiency of a new composite structure of resinoid and abrasive binder (diamond) in the abrasive microscopic machining of specimens K20 (ISO) sintered metal carbide specimens using experimental tools compared to the same type of extruded tool of the current domestic production from SC DIASFIN SA Bucharest.

Real-time testing of experimental tools has been performed.
From their analysis, the following conclusions can be drawn:

The increase of the hardener content of the E1 binder by $14.7 \%$ leads to a $15.2 \%$ increase in the microsacre yield compared to the E2 binder, while maintaining the same abrasive (CSi) and superabrasive (Dia) content, but with decreasing $3.7 \%$ of the resin content

Considering the hardness of the abrasive composite layer of the binder (binder matrix and diamond as reinforcement) as a mediation between mechanical hardness and abrasion capacity, it results that a superior hardener content complies with the retention capacity of the superabrasive with its friability characteristics, thus improving processing yield.

However, there is a limitation of the hardener content of too much amount, which fragile the binder and generates a premature wear of the abrasive layer. The very good compatibility of the superabrasive binder with the reference tool made with phenolic resinoid binder explains the superior processing yield achieved by it.

A "friable" diamond type generates by cutting new edges and cutting tips being compatible with a resinoid binder, while a stronger metal binder is recommended for incorporating a more "rounded" and more wear-resistant diamond type so that it retains its abrasion capacity with longer time before being expelled from the binder

- The size of the superabrasive grain influences the yield of the microassay by abrasion. Greater granulation abrays a higher volume of micro-shadows over the life of the active layer.

Thus, the D181 grain extraction grain achieves a $53 \%$ higher yield compared to the D126 superabrasive grain. The volume of used active layer $" \Delta V s$ " for processing the same volume of material in the sample " $\Delta \mathrm{Vw}$ " is inferior by $35 \%$ for the superabrasive with the D181 granulation compared to the D126 grain.

Also, the average linear wear " $\Delta$ rs" of the abrasive layer is $35 \%$ lower for the D181 superabrasive compared to the D126 grain.

- Superficial rugosity resulting from microabrasion varies directly with the size of the superabrasive grain. A finer grain generates a better surface quality, a lower surface roughness.

- Compatibility of the "disc-specimen" friction coupler surfaces; The "prior opening" of the abrasive layer by the binder exposition of the diamond granules is necessary to initiate the microabrasion process in optimum conditions.

In this regard, after the extrusion from the pressthermal treatment device, the surface of the disc is cleaned with a conventional abrasive brace or rectified with a correctional abrasive tool, generally SiC green. 
- Specialists consider that each superabrasive disc-friction disk in cms has tribological features related to the morphology of the extra-crystal crystal, the characteristics of the binder, its degree of compatibility with the superabrasive, and the physico-mechanical and structural characteristics of the cms parameters of the micro- lubrication and rigidity of the technological system.

Optimization of its operation can be done through multiple functional tests in laboratory and industrial applications. A great imprint in the evaluation of the microabrasion process is the imaging analysis of the abrasive layer over its lifetime, generally by SEM microscopy or atomic force.

Considering the similarity of sense between technological and tribological indicators, modern research considers superabrazing microassay a "tribo-technological" process.

The obvious economic benefits, together with the applicability to cms processing, compensate for the lower yield, recommending the new generation of polyamine resin resins as a technical solution and arguing industrial application at SC CARMESIN SA.

From preliminary economic calculations, the cost of a diamond disk with polyamine resinoid binder is about 350-400 lei, while the cost of a classic one from SC DIASFIN SA is 1,200 lei.

It is proposed to continue the research for the procedure of manufacturing the grinding tools with the new generation of binders and to extend the applications to new types of grinding tools.

\section{References}

[1] COJOCARU, Mihai. Production and processing of metallic powders. Matrix Rom Publishing House, 1998. Bucharest

[2] PÁLFALVI, Attila. Powder metallurgy. Technical Publishing House, 1988 Bucharest

[3] PĂUNOIU, Viorel. Technologies for the manufacture of powder parts. Galaţi,

[4] CĂLUGĂRU, G, APACHIŢEI, I, CĂLIMAN R. Amorphous metal powders: Advanced materials. Publishing House Plumb, 1995 Bacău.

[5] CIOCARDIA C, DRAGULANESCU, E, DRAGULANESCU, I, Sintered hard metal alloys Technical Publishing House, 1985, Bucharest

[6] DOMŞA, A. Technology of manufacturing of metal powders, Technical Publishing House, 19662.

[7] SURDEANU, T, PERNES, M. Sintered parts of metallic powders, Technical Publishing House, 1984 Bucharest

[8] SIMITI, Z. V. Technological properties in powder metallurgy, Encyclopedia Publishing House, 2000, Bucharest

[9] MUREŞAN, R. Powder metallurgy, U.T. Press, Cluj-Napoca, 2005

[10] GERMAN, R.M. Powder Metallurgy,Princeton,New Jersey,U.S.A.,1997

[11] NICA G., Powder Production and Use, Laboratory Guidance, 1998, Polytechnic University of Timisoara. 